\title{
Aboriginal Children and Their Caregivers Living with Low Income: Outcomes from a Two-Generation Preschool Program
}

\author{
Karen Benzies · Suzanne Tough $\cdot$ Nancy Edwards • \\ Richelle Mychasiuk · Carlene Donnelly
}

Published online: 14 July 2010

(c) The Author(s) 2010. This article is published with open access at Springerlink.com

\begin{abstract}
The development of preschool children of Aboriginal heritage is jeopardized by the inter-generational transmission of risk that has created, and continues to create, social disadvantage. Early intervention programs are intended to mitigate the impact of social disadvantage. Yet, evidence of the effectiveness of these programs for children of Aboriginal heritage is limited. The purpose of this study was to examine the effects of a two-generation, multi-cultural preschool program on 45 children of Aboriginal heritage and their caregivers. We used a singlegroup, pretest (program intake)/posttest (program exit) design with follow-up when the children were 7 years old. We used an observational measure of child receptive language (Peabody Picture Vocabulary Test-III) and caregiver-reported measures of child development (Nipissing District Developmental Screen), risk for child maltreatment (Adult-Adolescent Parenting Inventory; AAPI), parenting stress (Parenting Stress Index; PSI), self-esteem
\end{abstract}

\author{
K. Benzies ( $\square)$ \\ Nursing, University of Calgary, 2500 University Dr. N.W., \\ Calgary, Alberta T2N 1N4, Canada \\ e-mail: benzies@ucalgary.ca \\ S. Tough \\ Pediatrics/Community Health Sciences, University of Calgary, \\ Calgary, AB, Canada \\ N. Edwards \\ Epidemiology/Community Medicine, University of Ottawa, \\ Ottawa, ON, Canada \\ R. Mychasiuk \\ Nursing, University of Calgary, Calgary, AB, Canada \\ C. Donnelly \\ Calgary Urban Project Society (CUPS) Health and Education \\ Centres, Calgary, AB, Canada
}

(Rosenberg Self-Esteem scale; RSE), and life skills (Community Life Skills scale; CLS). Using paired $t$-tests we found statistically significant increases in child receptive language scores between intake and exit, and repeatedmeasures ANOVA showed that these improvements were maintained up to age 7 years. For caregivers, Pearson's correlations demonstrated that risk for child maltreatment, parenting stress, self-esteem, and life skills were stable over time. Results of this study suggest that children of Aboriginal heritage can benefit from participation in a twogeneration, multi-cultural preschool program. Their caregivers may have received greater benefit if issues of intergenerational transmission of the negative influences of residential schools were addressed as part of programming.

Keywords Aboriginal · Preschool children · Parents . Intervention studies · Poverty

\section{Introduction}

As a country, Canada takes pride in the fact that it is multicultural society providing equal opportunity to all citizens. Yet, not all Canadians have the same chance for health and prosperity. Recent studies have demonstrated the persistence of large inequities, especially for people of Aboriginal heritage (Ball 2008; Lavergne et al. 2008; Ring and Brown 2003; Statistics Canada 2004). According to the 2006 Canadian census, there were 1,172,785 individuals of Aboriginal heritage living in Canada, which comprises approximately $3.8 \%$ of the total population (Statistics Canada 2008). The same census reported that between 41 and $52 \%$ of Aboriginal children live in families with low income, as compared to only $17 \%$ of all Canadian children. Given that children under the age of 15 comprise $35 \%$ of 
the Aboriginal population, as compared to only $19 \%$ of the non-Aboriginal population (Ball 2008), Aboriginal poverty may have far-reaching effects on the functionality and sustainability of Canadian societies in the future. The gap in life expectancy between Aboriginal and non-Aboriginal populations is between 5 and 7 years (Ring and Brown 2003). Aboriginal children are 1.5 times more likely than non-Aboriginal children to die before their first birthday (Canadian Institute for Health Information 2004). Furthermore, Aboriginal children are seven times more likely to be born to an adolescent mother than other Canadian children; and one of the reasons that Aboriginal women give for leaving school early is to care for a child (Ball 2008; Guimond and Robitaille 2008). Currently, only half of Aboriginal children attend any sort of preschool program (Statistics Canada 2004). By Grade 4, Aboriginal children are over-represented (16\% higher than nonAboriginal children) by teachers as "not meeting expectations" (Ball 2008), and only 52\% will go onto complete high school (compared to $74 \%$ of the general population) (Statistics Canada 2004).

There is strong evidence that early intervention can prevent developmental delay, promote literacy, numeracy, and social competence, and improve school readiness, especially in disadvantaged families (Barnett and Hustedt 2005; Barnett and Ackerman 2006; Karoly et al. 1998; Karoly et al. 2005; McCain et al. 2007; Randall 2001; Young and Richardson 2007). Early intervention programs that target preschool children and their caregivers may be especially beneficial to improve outcomes. Such programs are typically called two-generation programs (St. Pierre et al. 1998). Yet there is limited evidence of outcomes for specifically children of Aboriginal heritage.

Aboriginal Head Start (AHS) is a two-generation preschool program inspired by the Head Start movement in the United States. AHS is a government funded program designed to reduce educational disparities between Aboriginal and non-Aboriginal children (Ball 2008). AHS provides a safe, supervised, and stimulating environment for young children, including adequate nutrition, and a place to learn socialization skills. AHS offers parenting education, life skills, and food preparation training (Ball 2008; Health Canada 2001; Statistics Canada 2004). Although there are some indications that AHS reduces the risk of a child repeating a grade, there have not been any systematic evaluations of program impacts on child development, health, or long-term outcomes for children of Aboriginal heritage or their caregivers (Ball 2008).

Similar to AHS, the Calgary Urban Project Society (CUPS), One World Child Development Centre (from here on in referred to as One World) is a two-generation, multicultural preschool program designed to provide comprehensive, integrated early intervention to simultaneously address the needs of preschool children and their caregivers living with low income. One World aims to provide a safe, supportive, stable environment that is conducive to learning. Each year, a total of 50 preschool children are enrolled. Of these, approximately $36 \%$ were of Aboriginal heritage. The purpose of this study was to evaluate outcomes for children of Aboriginal heritage and their caregivers who enrolled at One World. The research questions were: What is the effect of a two-generation preschool program on receptive language skills in children of Aboriginal heritage living in families with low income? What is the effect of the program on parent-reported global child development? What is the effect of the program on caregivers' perceptions of (a) risk for child maltreatment, (b) parenting stress (c) self-esteem, and (d) management of daily life skills? For the purpose of this study, 'caregiver' refers to a biological parent or other kin caregiver, such as a grandmother or auntie.

Rooted within a framework of ecological theory (Bronfenbrenner 2005), two-generation programs are believed to be of benefit in situations where the needs of a population interact within complex environmental systems (Guralnick 2001). The underlying premise of One World assumed involvement of the family as the primary socializing agent and context for the child's development (Unger et al. 2004). Caregiver involvement was aimed at improving parenting and the family environment to operate synergistically with child-focused early intervention programming to enhance short- and longer-term gains for the child and caregiver.

\section{Method}

We used a single group, pretest/posttest design with follow-up when the children were 7 years old. We recruited preschool children and their caregivers to the program through agencies serving families with low income, and by word-of-mouth. We carried out our study in parallel, but independent of One World programming. There were separate eligibility criteria for enrolment in the program and participation in the study. Children and their caregivers were eligible to attend the program if they had a low income, and the child had one or more risks of developmental delay. Risks included (a) caregiver mental illness, (b) addictions within the family, and (c) social isolation. Criteria to remain in the program were (a) child attended regularly, (b) caregiver attended a 6-week parent education course, and (c) caregiver volunteered periodically to supervise children on the school bus. Children in foster care were ineligible, unless an older sibling attended the program previously. Children and their caregivers were eligible to participate in the study if they were enrolled in 
the program for at least 3 consecutive months. We selected 3 months so that the child had a minimum exposure to early intervention programming and the caregiver completed the required education component.

\section{Participants}

Between December 2002 and September 2008, 45 children of Aboriginal heritage and 38 caregivers participated in the study. See Table 1 for socio-demographic characteristics. Twelve children and 7 caregivers were available for follow-up at 7 years. Of the 45 children with data at intake, 10 were in foster or kin care by the age of 7 years. We found no significant differences in age at intake $(p=.35)$, education level $(p=.68)$, marital status $(p=.20)$ or child welfare involvement $(p=.28)$ for caregivers with data at 7 years and those without. Although we used birthday cards, reminder refrigerator magnets, and set up a social networking site for the study, retention was challenging. A contributor to the low retention rate at follow-up was the refusal of children's services in Alberta to allow visits to children placed in foster care. Where families had relocated to other provinces in Canada, these visits were allowed. An institutional ethics review board approved the study. All caregivers who were eligible for the program consented to participate in the study, and accepted a gift certificate at each data collection point to recognize their contribution.

Table 1 Socio-demographic characteristics of children and their caregivers

\begin{tabular}{lrr}
\hline & $N$ & $\begin{array}{l}\text { Mean (SD) } \\
\text { Frequency } \\
(\%)\end{array}$ \\
\hline Child & & \\
Sex (\% male) & 45 & $25(56 \%)$ \\
Age at intake (months) & 45 & $45.80(9.34)$ \\
English is first language & 42 & $40(95.0 \%)$ \\
In foster care by age 7 & 45 & $10(22.2 \%)$ \\
Caregiver & & \\
Age at intake (years) & 38 & $30.00(5.76)$ \\
Relationship to child (\% biological mother) & 38 & $36(94.7 \%)$ \\
Marital status (\% married or common-law) & 38 & $22(57.9 \%)$ \\
Completed high school & 38 & $12(31.6 \%)$ \\
Primary source of income (\% receiving & 38 & $19(50.0 \%)$ \\
$\quad$ government support) & & \\
Housing situation is stable & 38 & $21(55.2 \%)$ \\
As a child, the caregiver had a child & 38 & $22(57.9 \%)$ \\
$\quad$ welfare file open & & \\
As a parent, the caregiver has a child & 38 & $26(68.4 \%)$ \\
$\quad$ welfare file open & & \\
\hline
\end{tabular}

One World

Although, the implementation of One World predated the creation of the Aboriginal Ethics Council (Interagency Advisory Panel on Research Ethics 2009), the Aboriginal community was integral to development of the program mandate and design. During the design of the program, a caregiver advisory committee met regularly with program developers to share the cultural and spiritual values of the Aboriginal peoples. To accommodate the diverse needs of caregivers of Aboriginal heritage, flexibility in the delivery of child and parent programming was incorporated into the design. An Aboriginal grandmother who attended the CUPS Family Resource Centre with her children and grandchildren selected One World as the name for the new program. The program has three main components: early childhood education, parent education, and family support.

\section{Early Childhood Education}

The center-based, preschool/kindergarten program was designed to prevent developmental delays and promote literacy, numeracy, and social competence (Cooper and Hoffart 2002). The curriculum focused on the interests of children to motivate learning (Gandini 1993; Hewett 2001), and daily classroom routine was important. The teacher-tochild ratio was maintained at 1:8. All teachers had formal education (certificate, diploma, or university degree) and experience in early childhood education; professional development occurred throughout the year. Teachers visited the child and caregiver at home four times per year, and caregivers were encouraged to participate in school activities. The program was a clinical practice site for undergraduate students from nursing, social work, and early childhood education.

Children attended classes 4 days per week, $5 \mathrm{~h}$ per day from early September until late June, with the option to attend recreational activities during the summer. Breakfast, lunch, and snacks were designed around the preschool-age Canada Food guide (Health Canada 2007) and provided $65 \%$ or greater of the child's total daily nutritional requirements (unpublished data). School bus transportation to the program was provided because low income families were geographically dispersed (Heisz and McLeod 2004). Buses were equipped with child car seats and supervised by volunteer caregivers.

Children identified by their teachers or through screening as a part of this study, were referred for further assessment by an on-site team of licensed developmental specialists (occupational, physical, speech and language therapists, and psychologists), for which One World received additional government funding. Community health nurses and developmental pediatricians held regular clinics on site. Dental, 
hearing, and vision screenings were conducted off-site as field trips, with the services donated by private practices and college training programs. After kindergarten, a family support worker assisted the children and their families with the transition to their neighborhood schools.

\section{Parent Education}

Parent education included a mandatory 6-week series of parenting and life skills classes at program entry. During this series, group and one-on-one parenting classes addressed topics such as positive parenting behaviors and strategies to promote optimal child development. Additional standardized parenting programs, such as Nobody's Perfect (Health Canada 2003) and 1, 2, 3, Magic (Phelan 2004), were offered on-site by certified facilitators. Life skills classes addressed topics such as managing stress, substance abuse, household and family routines, budgeting, personal health and wellbeing, self-esteem, healthy relationships, and job skills. Attendance was optional at other parent education sessions that took place throughout the year. These included (a) how to apply for public transit subsidies; (b) how to cook nutritious food on a small budget; and (c) crafts, such as making dream catchers. The parent advisory committee met monthly to provide advice about programming.

\section{Family Support}

Family support was provided through a minimum of four home visits per year by a registered social worker. Families in need received more intensive support (i.e., extra home visits and telephone contacts). Family support strategies included goal setting, counseling, and advocacy to access food, stable housing, and legal and child welfare systems.

\section{Procedures}

Children and their caregivers were assessed when they entered (intake), when they exited (exit) the program, and when the child was 7 years old. Child observational measures were collected in a designated quiet space on site, while 7 year visits were collected in the family home by research assistants who were trained in developmental screening and maintained inter-rater reliabilities of $98 \%$ or greater. Caregiver reported measures were completed as paper and pencil questionnaires by biological parents, only.

\section{Child Measures}

\section{Peabody Picture Vocabulary Test 3rd edition (PPVT-III)}

The PPVT-III (Dunn and Dunn 1997) is a standardized $(M=100 ; \mathrm{SD}=15)$, observational measure of receptive language for individuals over the age of $2 \frac{1}{2}$ years. Higher scores indicate greater receptive language skill. The PPVTIII has been used on samples of preschool and kindergarten children living in poverty; the norms accurately represent children from low income backgrounds (Washington and Craig 1999, 2004). The PPVT has been used widely as a proxy for school readiness (Downie 2000; Human Resources and Social Development Canada, \& Statistics Canada 1996; Kohen et al. 2002).

\section{Nipissing District Developmental Screen (NDDS)}

The NDDS (Windsor Essex County Health Unit 2002) is a brief caregiver-report of eight developmental areas: gross motor, fine motor, vision, hearing, communication, speech and language, social-emotional behaviors, selfhelp skills, and cognitive. Binary responses (yes/no) indicate whether the child has achieved age-appropriate, major developmental milestones up to 6 years. The developers of the NDDS suggest that one or more no items warrants referral for further assessment (Windsor Essex County Health Unit 2002). Inter-rater reliability between reports of a parent and non-parent adult familiar with a child was $71 \%$. Test-retest reliability over 6 months was $65 \%$. Concurrent validity between NDDS and Ages and Stages Questionnaire (ASQ) second edition was $78.3 \%$ (Dahinten and Ford 2004).

\section{Caregiver Measures}

\section{Parenting Stress Index-Short Form (PSI-SF)}

The PSI-SF (Abidin 1995) is a 36-item, self-report designed to measure parenting stress on four subscales: (a) parental distress, (b) parent-child dysfunctional interaction, (c) difficult child, and (d) defensive responding. The PSI-SF uses a 5-point Likert scale 1 (strongly agree) to 5 (strongly disagree). Items on the PSI-SF are derived from the full PSI, which has well established reliability and validity (Abidin 1995). Clinical cut-offs vary by subscale: (a) parental distress $\geq 33$, (b) parent-child dysfunctional interaction $\geq 26$, (c) difficult child $\geq 33$, (d) total score $\geq 86$, and (e) defensive responding $\leq 10$. Cronbach's alphas reported for the subscales were .87 for parental distress, .80 for parent-child dysfunctional interaction, .85 for difficult child, and .91 for total stress. For this study, Cronbach's alphas for the subscales were $.86, .85, .83$, and .92 , respectively.

\section{Rosenberg Self-Esteem (RSE) Scale}

The RSE (Rosenberg 1965) is a 10-item, uni-dimensional, self-report measure of global self-esteem on a 4-point 
Guttman scale 1 (strongly agree) to 4 (strongly disagree); higher scores indicate greater self-esteem. For this study, the RSE item responses were summed to create a total score. A total score of $<15$ is considered in the clinical range. Test-retest reliability was .85 over 2 weeks. Convergent validity with the Coopersmith Self-Esteem Inventory (Coopersmith 1967) has been established $(r=.60)$. Cronbach's alphas ranged from .74 to .80 in different studies (Rosenberg 1965). For this study, Cronbach's alpha was .88 .

\section{Community Life Skills Scale (CLSS)}

The CLSS is an adaptation of the 33-item, binary (yes/no) scale originally developed by Barnard (1991) to measure daily life skills in negotiating the use of community resources on six subscales: (a) transportation, (b) budgeting, (c) support services, (d) support involvement, (e) interests and hobbies, and (f) regularity, organization and routines. The original interview version of the CLSS was time-consuming to administer. In the adaptation, the CLSS items were reworded to enable the individual to self-complete the scale. The yes responses are summed to create subscale and total scores; higher scores indicating greater ability to use community resources. A total score of $<18$ is considered worrisome (Barnard 1991). Cronbach's alphas have been reported to range from .63 to .69 (Barnard 1991). For this study, Cronbach's alpha for the total score was .80 .

\section{Adult-Adolescent Parenting Inventory-2 (AAPI-2)}

The AAPI-2 (Bavolek and Keene 2001) is a 40-item, selfreport, questionnaire designed to assess attitudes about child rearing among adult and adolescent parent and preparent populations. The AAPI-2 provides an index of risk for practicing parenting behaviors known to be linked with child maltreatment. There are five subscales: (a) expectations of children, (b) empathy towards children's needs, (c) use of corporal punishment as a means of discipline, (d) parent-child role responsibilities, and (e) children's power and independence. Responses on a 5-point Likert scale range from 1 (strongly agree) to 5 (strongly disagree); higher scores indicate lower risk for child maltreatment. A subscale score below 5 is considered to be in the clinical range. There is no total score computed for this measure. Cronbach's alphas reported for Form A subscales range from .80 to .92 (Bavolek and Keene 2001). For this study, Cronbach's alphas for the subscales ranged from .47 (power and independence) to .91 (role reversal).

\section{Results}

\section{Children}

Children improved their receptive language scores by 10 points between intake $(M=88.37 ; \mathrm{SD}=15.78)$ and exit $(M=98.03 ; \mathrm{SD}=12.65), t(37)=5.228, p=.001, \mathrm{CI}$ $5.92,13.40$. See Table 2. On average, children continued to score slightly below the typically developing child at program exit. Of note, the standard deviation decreased between intake and exit suggesting that participation at One World decreased the variability in receptive language scores over time. A one-way repeated-measures ANOVA demonstrated that children had significantly better receptive language scores at exit and 7 years than they did at intake, $F(2,22)=6.67, p=.005$. Repeated-measures $t$-tests demonstrated that there was a significant improvement in receptive language scores between intake and exit, $t(11)=3.480, p=.005$, and intake and 7 years, $t(11)=$ 2.234, $p=.047$, but there was no change in receptive language scores between exit and the 7 year follow-up, $t(11)=1.360, p=.201$. See Table 3. Between intake and exit, fewer children were at risk for global developmental delay. At intake, 21 children (57\%) were flagged on the NDDS by their caregiver as failing to achieve age appropriate developmental milestones; at exit, only 13 children $(35 \%)$ were flagged.

\section{Caregivers}

Caregivers' scores were highly correlated between intake and exit (Pearson's correlations ranged from $r=.30$ [PSIDysfunctional Interaction] to .83 [RSE]). See Table 4. Furthermore, caregiver scores were highly stable up to the

Table 2 Scores on child receptive language and global development between intake and exit

\begin{tabular}{lccc}
\hline Measure & $N$ & $\begin{array}{l}\text { Intake } \\
\text { Mean (SD) } \\
\text { Frequency (\%) }\end{array}$ & $\begin{array}{l}\text { Exit } \\
\text { Mean (SD) } \\
\text { Frequency (\%) }\end{array}$ \\
\hline PPVT-III & 38 & $88.37(15.78)$ & $98.03(12.65)$ \\
NDDS & 37 & $21(57 \%)$ & $13(35 \%)$ \\
\hline
\end{tabular}

PPVT-III Peabody picture vocabulary test 3rd edition, NDDS Nipissing district developmental screen

Table 3 Scores on child receptive language at intake, exit and 7 years of age

\begin{tabular}{lllll}
\hline Measure & $N$ & $\begin{array}{l}\text { Intake } \\
\text { Mean (SD) }\end{array}$ & $\begin{array}{l}\text { Exit } \\
\text { Mean (SD) }\end{array}$ & $\begin{array}{l}\text { Follow-up } \\
\text { Mean (SD) }\end{array}$ \\
\hline PPVT-III & 12 & $85.67(18.29)$ & $100.08(12.42)$ & $95.17(11.33)$ \\
\hline
\end{tabular}

PPVT-III Peabody picture vocabulary test 3 rd edition 
Table 4 Means, standard deviations, and pearson's correlations between intake and exit for caregivers' scores on Adult Adolescent Parenting Inventory, Parenting Stress Index, Rosenberg Self-Esteem scale, and Community Life Skills scale

\begin{tabular}{lclll}
\hline Measure & $N$ & $\begin{array}{l}\text { Intake } \\
\text { Mean (SD) }\end{array}$ & $\begin{array}{l}\text { Exit } \\
\text { Mean (SD) }\end{array}$ & $r$ \\
\hline $\begin{array}{l}\text { AAPI inappropriate } \\
\quad \text { expectations }\end{array}$ & 23 & $6.48(1.5)$ & $6.83(1.6)$ & $.72^{* * *}$ \\
AAPI empathy & 23 & $5.61(1.4)$ & $5.48(1.7)$ & $.59^{* *}$ \\
AAPI corporal punishment & 23 & $6.13(1.2)$ & $6.04(1.2)$ & $.42^{*}$ \\
AAPI role reversal & 23 & $5.61(1.8)$ & $6.00(1.6)$ & $.57^{* *}$ \\
AAPI power/independence & 23 & $5.04(1.6)$ & $5.57(2.1)$ & $.54^{* *}$ \\
PSI parental distress & 23 & $27.43(5.2)$ & $27.39(6.5)$ & $.64^{* *}$ \\
PSI dysfunctional interaction & 23 & $19.96(4.8)$ & $21.17(5.6)$ & .30 \\
PSI difficult child & 23 & $27.43(6.3)$ & $25.78(7.4)$ & .36 \\
PSI defensive responding & 23 & $16.30(3.6)$ & $16.00(3.7)$ & $.53^{* *}$ \\
PSI total & 23 & $74.83(12.5)$ & $74.35(14.9)$ & $.43^{*}$ \\
RSE & 23 & $21.48(4.8)$ & $21.00(4.3)$ & $.83^{*}$ \\
CLSS & 21 & $23.76(4.7)$ & $26.10(3.8)$ & $.55^{* *}$ \\
\hline AAPI Adult adolescent & & & &
\end{tabular}

AAPI Adult adolescent parenting inventory, PSI parenting stress index, RSE Rosenberg Self-Esteem scale, CLSS Community Life Skills Scale

$* p<.05 ; * * p<.01$

7 year follow-up visit (correlations ranged from $r=.40$ [AAPI-Power/Independence] to .97 [PSI-Parental Distress]). See Table 5. This suggests that there was little change in Aboriginal caregivers' perceptions of parenting stress, self-esteem, acquisition of daily life management skills or risk for child maltreatment between intake, exit, and follow-up.

\section{Discussion}

For children of Aboriginal heritage, participation in a twogeneration preschool program had a statistically significant positive effect on their receptive language scores. On average, children gained nearly 10 standard deviation units during their participation at One World and this improvement was sustained following exit from the program until at least 7 years of age. This increase is somewhat better than the well known Abecedarian Project, which demonstrated an 8-point increase in cognitive skills (Campbell et al. 2002), and was similar to the universal pre-K program for Native American children in Oklahoma, which found a 9-point increase on the Letter-Word Identification tests (Gormley et al. 2005). These results suggest that One World demonstrates outcomes at least as good as or better than other established early intervention programs for children at risk. Furthermore, these positive effects are sustained after the children leave the program until at least 7 years of age.
Table 5 Mean scores and correlations for caregiver risk for child maltreatment, stress, self-esteem and life skills between intake and 7 year follow-up

\begin{tabular}{lllll}
\hline Measure & $N \begin{array}{l}\text { Intake } \\
\text { Mean (SD) }\end{array}$ & $\begin{array}{l}\text { Follow-up } \\
\text { Mean (SD) }\end{array}$ & $r$ \\
\hline $\begin{array}{l}\text { AAPI inappropriate } \\
\text { expectations }\end{array}$ & 7 & $6.71(1.7)$ & $7.14(1.95)$ & $.77^{*}$ \\
AAPI empathy & 7 & $5.57(1.1)$ & $5.71(2.0)$ & $.80^{*}$ \\
AAPI corporal punishment & 7 & $5.43(1.13)$ & $5.86(1.1)$ & .75 \\
AAPI role reversal & 7 & $6.14(1.7)$ & $6.43(3.0)$ & .61 \\
AAPI power/independence & 7 & $4.86(1.7)$ & $5.43(1.6)$ & .40 \\
PSI parental distress & 7 & $27.29(6.5)$ & $27.86(8.3)$ & $.97 * *$ \\
PSI dysfunctional interaction & 7 & $19.71(5.8)$ & $20.57(5.4)$ & .42 \\
PSI difficult child & 7 & $28.43(9.3)$ & $28.29(11.35)$ & .59 \\
PSI defensive responding & 7 & $15.57(3.6)$ & $16.71(4.8)$ & $.79 *$ \\
PSI total & 7 & $75.43(17.0)$ & $76.71(23.3)$ & $.91^{*} *$ \\
Rosenberg self-esteem & 7 & $21.71(5.7)$ & $20.71(4.5)$ & $.78^{*}$ \\
Community life skills scale & 6 & $20.33(6.0)$ & $26.83(2.7)$ & $.92^{*}$ \\
\hline
\end{tabular}

Scores are for those caregivers with complete data at intake and follow-up

AAPI Adult adolescent parenting inventory, PSI parenting stress index

$* p<.05 ; * * p<.01$

However, it is concerning that, even after participating in intensive early childhood intervention, on average, these children continued to score below the typically developing child on receptive language. On a positive note, we have found that the amount of time children of Aboriginal heritage spend at One World is positively related to receptive language scores between program intake and exit (Benzies et al. 2010). Together, these results suggest that there may be increased benefits of early intervention programming for these children if programming begins earlier and continues throughout the preschool years. This assertion is consistent with other advocates of early childhood intervention who suggest that preschool is too late for children who have serious risks for developmental delays (McCain et al. 2007). Given the high rates of poverty (Ball 2008) and poor educational attainment (Statistics Canada 2004), intensifying support for early childhood development may increase the chances of school success for children of Aboriginal heritage.

Consistent with the observational measures of child receptive language skills, caregivers reported a greater proportion of children achieved their global developmental milestones by the time they left One World. While issues abound with caregiver reports (Morsbach and Prinz 2006), these findings may represent true improvements in global development, as an increased knowledge of typical child development is a core concept in the parent education curriculum. Thus, improvements in caregiver-reported 
development may have been the result of increased parental awareness of developmental milestones.

While One World is effective for children of Aboriginal heritage, contrary to expectations, caregiver involvement in One World had limited effect on caregiver outcomes (risk for child maltreatment, parenting stress, self-esteem, and daily life skills). Considerable deliberation about this finding has led us to believe that we may not be measuring the appropriate or relevant constructs for caregivers of Aboriginal heritage. Alternatively, it may be that personal and family issues were inter-generational, as suggested by the high proportion of participants who were involved in child welfare as children and as caregivers. This finding is consistent with other research about inter-generational transmission of risk in heterogeneous Canadian and US samples (Bifulco et al. 2002; Serbin and Karp 2004). Even with a high quality, strengths-based program, caregivers of Aboriginal heritage demonstrated limited improvements in risk for child maltreatment and psychosocial well-being. Stories shared by caregivers gave voice to the origin of much of this adversity. A lifetime of loss and grieving with insufficient resources to support positive early development leads to maladaptive coping and high risk behaviors. Thus, interventions for caregivers of Aboriginal heritage may need to focus more on spiritual and emotional healing, rather than on changing specific parenting behaviors, in order to penetrate the deeply rooted challenges within the families and societal interactions of these individuals. Limitations included the small sample, which precluded subgroup analyses by child gender. Additionally, the lack of a control group is a design limitation that should be addressed in future studies.

As designed and implemented, this two-generation preschool program holds promise to promote optimal outcomes for children of Aboriginal heritage. However, more work is needed to explore the unique needs of their caregivers and how to better measure success in this population. While AHS is targeted towards Aboriginal children and their families specifically, One World has demonstrated the ability to improve developmental outcomes for Aboriginal children within a culturally diverse environment. Thus, children of Aboriginal heritage may benefit from enrolment in any evidence-based, two-generation preschool programs, regardless of cultural composition. This may maximize accessibility to preschool programs and increase the value of investments in early intervention programming.

Acknowledgments We would like to thank all of the children and parents who participated in the One World study. Specifically we would like to thank Mike Panther Bone: He lives on in his brother John and their children. Nancy Edwards holds a Nursing Chair from the Canadian Health Services Research Foundation, the Canadian Institutes of Health Research and the Government of Ontario.
Funding for this study was provided by Max Bell Foundation, Grant: 07-C-40.

Open Access This article is distributed under the terms of the Creative Commons Attribution Noncommercial License which permits any noncommercial use, distribution, and reproduction in any medium, provided the original author(s) and source are credited.

\section{References}

Abidin, R. R. (1995). Parenting Stress Index: Professional manual (3rd ed.). Odessa, FL: Psychological Assessment Resources.

Ball, J. (2008). Promoting equity and dignity for Aboriginal children in Canada. IRPP Choices, 14(7), 1-27.

Barnard, K. (1991). Community life skills scale. Seattle, WA: NCAST Publications.

Barnett, W. S., \& Ackerman, D. J. (2006). Costs, benefits, and longterm effects of early care and education programs: Recommendations and cautions for community developers. Community Development: Journal of the Community Development Society, 37(2), 86-100.

Barnett, W., \& Hustedt, J. (2005). Head Start's lasting benefits. Infants and Young Children, 18(1), 16-24.

Bavolek, S. J., \& Keene, R. G. (2001). Adult-adolescent parenting inventory (AAPI-2): Administration and development handbook (3rd ed.). Asheville, NC: Family Development Resources Inc.

Benzies, K., Edwards, N., Tough, S., Nagan, K., Mychasiuk, R., Keown, L. A., et al. (2010). Effects of a two-generation preschool programme on receptive language skill in low-income Canadian children. Early Child Development and Care, 28 January 2010(iFirst).

Bifulco, A., Moran, P. M., Ball, C., Jacobs, C., Baines, R., Bunn, A., et al. (2002). Childhood adversity, parental vulnerability and disorder: Examining inter-generational transmission of risk. Journal of Child Psychology and Psychiatry, 43(8), 1075-1086.

Bronfenbrenner, U. (2005). The biological theory of human development. In U. Bronfenbrenner (Ed.), Making human beings human: Biological perspectives on human development (pp. 3-15). Thousand Oaks, CA: Sage Publications.

Campbell, F. A., Ramey, C. T., Pungello, E., Sparling, J., \& MillerJohnson, S. (2002). Early childhood education: Young adult outcomes from the Abecedarian Project. Applied Developmental Science, 6(1), 42-57.

Canada, Health. (2001). Aboriginal Head Start in urban and northern communities: Program and participants, 2000. Ottawa, ON: Health Canada.

Canada, Health. (2003). Working with nobody's perfect: A facilitator's guide (3rd ed.). Ottawa, ON: Canadian Government Publishing.

Canadian Institute for Health Information. (2004). Aboriginal peoples health. Ottawa, ON: Canadian Population Health Initiative.

Cooper, M., \& Hoffart, I. (2002). One World Child Development Centre evaluation design. Calgary: AB. (Author).

Coopersmith, S. (1967). Coopersmith self-esteem inventory. San Francisco, CA: W. H. Freeman \& Co.

Dahinten, S., \& Ford, L. (2004). Validation of the Nipissing District Developmental Screen for Use with Infants and ToddlersWorking Paper. Vancouver, British Columbia: University of British Columbia.

Downie, R. (2000). Living on the edge: A profile of low-income workers in Calgary. Calgary, AB: United Way of Calgary and Area.

Dunn, L. M., \& Dunn, L. M. (1997). Peabody picture vocabulary test-third edition manual. Circle Pines, MN: American Guidance Services. 
Gandini, L. (1993). Fundamentals of the Reggio Emilia approach to early childhood education. Young Children, 49(1), 4-17.

Gormley, W., Gayer, T., Phillips, D. A., \& Dawson, B. (2005). The effects of universal pre-k on cognitive development. Developmental Psychology, 41(6), 872-884.

Guimond, E., \& Robitaille, N. (2008). When teenage girls have children: Trends and consequences, Aboriginal youth and Canada's future. Horizons, 10(1), 49-51.

Guralnick, M. J. (2001). A developmental systems model for early intervention. Infants \& Young Children: An Interdisciplinary Journal of Special Care Practices, 14(2), 1-18.

Health Canada. (2007). Eating well with Canada's food guide (No. Cat: H164-38/1-2007E). Ottawa, ON: Minister of Health.

Heisz, A., \& McLeod, L. (2004). Low-income in census metropolitan areas, 1980-2000. Ottawa, ON: Statistics Canada.

Hewett, V. M. (2001). Examining the Reggio Emilia approach to early childhood education. Early Childhood Education Journal, 29, 95-100.

Human Resources and Social Development Canada, \& Statistics Canada. (1996). Growing up in Canada: National longitudinal survey of children and youth. Ottawa, ON: Statistics Canada.

Interagency Advisory Panel on Research Ethics. (2009). Chapter 9: Research involving Aboriginal people in Canada. Ottawa, ON.

Karoly, L. A., Greenwood, P. W., Everingham, S. M. S., Hoube, J., Kilburn, M. R., Rydell, C. P., et al. (1998). Investing in our children: What we know \& don't know about the costs \& benefits of early childhood interventions. Santa Monica, CA: RAND Corporation.

Karoly, L. A., Kilburn, M. R., \& Cannon, J. S. (2005). Early childhood interventions: Proven results, future promise. Santa Monica, CA: RAND Corporation.

Kohen, D. E., Brooks-Gunn, J., Leventhal, T., \& Hertzman, C. (2002). Neighborhood income and physical and social disorder in Canada: Associations with young children's competencies. Child Development, 73(6), 1844-1860.

Lavergne, C., Dufour, S., Trocme, N., \& Larrrivee, M. (2008). Visible minority, aboriginal and caucasian children investigated by Canadian Protective Services. Child Welfare, 87(2), 59-76.

McCain, M. N., Mustard, F. J., \& Shanker, S. (2007). Early years study 2: Putting science into action. Toronto, ON: Council for Early Child Development. (C. f. E. C. Development).

Morsbach, S., \& Prinz, R. (2006). Understanding and improving the validity of self-report of parenting. Clinical Child and Family Psychology Review, 9(1), 1-21.
Phelan, T. (2004). 1-2-3 Magic: Effective discipline for children 2-12. Glen Ellyn, IL: Parentmagic.

Randall, P. E. (2001). Investing in our Children: What we know and don't know about the costs and benefits of early childhood interventions. Social Work \& Social Sciences Review, 9(1), 68.

Ring, I., \& Brown, N. (2003). The health status of indigenous peoples and others. British Medical Journal, 327, 404-405.

Rosenberg, M. (1965). Society and the adolescent self-image. Princeton, NJ: Princeton University Press.

Serbin, L. A., \& Karp, J. (2004). The intergenerational transfer of psychosocial risk: Mediators of vulnerability and resilience. Annual Review of Psychology, 55(1), 333-361.

St. Pierre, R. G., Layzer, J. I., Barnes, H. V., Barnett, W. S., \& Boocock, S. S. (1998). Regenerating two-generation programs. In W. Barnett, S. Boocock, \& S. Spence (Eds.), Early care and education for children in poverty: Promises, programs, and long-term results (pp. 99-121). Albany: University of New York Press.

Statistics Canada. (2004). A portrait of aboriginal children living in non-reserve areas: Results from the 2001 aboriginal peoples survey. Ottawa, ON: Housing, Family and Social Statistics Division.

Statistics Canada. (2008). Aboriginal peoples in Canada 2006: Inuit, Metis and First Nations, 2006 census. Ottawa, Ontario: Statistics Canada.

Unger, D. G., Tressell, P. A., Jones, C. W., \& Park, E. (2004). Involvement of low-income single caregivers in child-focused early intervention services: Implications for caregiver-child interaction. Family Relations, 53(2), 210-218.

Washington, J., \& Craig, H. (1999). Performances of at-risk, African American preschoolers on the Peabody Picture Vocabulary TestIII. Language, Speech and Hearing Services in Schools, 30, $75-82$.

Washington, J., \& Craig, H. (2004). A language screening protocol for use with young African American children in urban settings. American Journal of Speech-Language Pathology, 13(4), 329-340.

Windsor Essex County Health Unit. (2002). Nipissing District Developmental Screen. Retrieved February 3, 2006, from http://www.wechealthunit.org/ WECHU_RLink_Frameset.asp?RLinkID=174.

Young, M. E., \& Richardson, L. M. (2007). Early child development: From measurement to action-A priority for growth and equity. Washington, DC: The World Bank. 